\title{
Cycling in degradation of organic polymers and uptake of nutrients by a litter-degrading fungus
}

\author{
Aurin M. Vos (D), ${ }^{1,2^{* \dagger}}$ Robert-Jan Bleichrodt ${ }^{(D)},{ }^{1 \dagger}$ \\ Koen C. Herman ${ }^{1 D},{ }^{1 \dagger}$ Robin A. Ohm, ${ }^{1}$ \\ Karin Scholtmeijer (D), ${ }^{3}$ Heike Schmitt D, ${ }^{4}$ \\ Luis G. Lugones ${ }^{1}{ }^{1}$ and Han A. B. Wösten (iD) \\ ${ }^{1}$ Microbiology, Department of Biology, Utrecht \\ University, Utrecht, the Netherlands. \\ ${ }^{2}$ Wageningen Plant Research, Wageningen UR, \\ Wageningen, the Netherlands. \\ ${ }^{3}$ Plant Breeding, Wageningen University and Research, \\ Wageningen, the Netherlands. \\ ${ }^{4}$ Institute for Risk Assessment Sciences, Utrecht \\ University, Utrecht, the Netherlands.
}

\section{Summary}

Wood and litter degrading fungi are the main decomposers of lignocellulose and thus play a key role in carbon cycling in nature. Here, we provide evidence for a novel lignocellulose degradation strategy employed by the litter degrading fungus Agaricus bisporus (known as the white button mushroom). Fusion of hyphae allows this fungus to synchronize the activity of its mycelium over large distances $(50 \mathrm{~cm})$. The synchronized activity has a 13-h interval that increases to $20 \mathrm{~h}$ before becoming irregular and it is associated with a 3.5-fold increase in respiration, while compost temperature increases up to $2{ }^{\circ}$. Transcriptomic analysis of this burst-like phenomenon supports a cyclic degradation of lignin, deconstruction of (hemi-) cellulose and microbial cell wall polymers, and uptake of degradation products during vegetative growth of $A$. bisporus. Cycling in expression of the ligninolytic system, of enzymes involved in saccharification, and of proteins involved in nutrient uptake is proposed to provide an efficient way for degradation of substrates such as litter.

Received 16 July, 2020; revised 25 October, 2020; accepted 26 October, 2020. *For correspondence. E-mail aurin.vos@ wur.nl; Tel. +31 317480979; Fax +31 317418094. These authors contributed equally to this work.

\section{Introduction}

Mushroom forming fungi play a key role in nature and human society (Grimm and Wösten, 2018). For instance, they produce edible and medicinal fruiting bodies and play a pivotal role in cycling of carbon in nature. The latter is illustrated by the fact that they are the main decomposers of lignocellulose, the most abundant terrestrial organic material. This complex is found in wood and litter and consists of cellulose, hemicellulose and lignin. Brown rot fungi mostly modify lignin and degrade carbohydrates, while white rots simultaneously degrade lignin and carbohydrates or selectively (i.e. predominantly) degrade lignin (Worrall et al., 1997; Riley et al., 2014; Schilling et al., 2015). Brown and white rot wood degrading fungi use different types of radical chemistry to modify and degrade lignin (ten Have and Teunissen, 2001; Hammel et al., 2015), thereby exposing (hemi-) cellulose to the action of carbohydrate-active enzymes (CAZYs; enzymes involved in breakdown or synthesis of polysaccharides).

Recently, it was found that the mycelium of mushroom forming brown rot fungi spatially separate the radical generating Fenton chemistry from CAZYs (Zhang et al., 2016, 2019; Presley and Schilling, 2017; Castaño et al., 2018). The outer $5 \mathrm{~mm}$ of the colony of brown rots like Postia placenta generate $\bullet \mathrm{OH}$ radicals using the Fenton reaction, while the inner $15-35 \mathrm{~mm}$ regions of the colony secrete the bulk of (hemi-) cellulases. This spatial separation would prevent inactivation of these enzymes by radical oxygen species generated by Fenton chemistry. In addition, the radical pre-treatment of cell walls may facilitate the activity of CAZYs (Castaño et al., 2018; Zhang et al., 2019).

White rots may also make use of Fenton chemistry to attack lignocellulose, but it is not the main mechanism. These fungi mineralize lignin using a ligninolytic system that includes oxidoreductases like lignin peroxidase, manganese peroxidase $(\mathrm{MnP})$, and/or versatile peroxidase, and possibly laccase (LCC) as well (ten Have and Teunissen, 2001; Hammel et al., 2015). The peroxidases use $\mathrm{H}_{2} \mathrm{O}_{2}$ that is generated by oxidases like glyoxal oxidase, but it may also arise from secondary reactions with organic acids like oxalate (Kersten and Kirk, 1987; Urzúa et al., 1998). As a result, small radical intermediates are 
produced that penetrate lignocellulose and attack lignin directly or indirectly by facilitating secondary reactions, possibly including lipid peroxidation in the case of $\mathrm{MnP}$ (Hofrichter, 2002). Radicals generated by the ligninolytic system of white rots may result in a more gentle radical treatment of lignocellulose as not all radicals species that are associated with white rot match the reactivity of $\bullet \mathrm{OH}$ radicals. This may explain why white rots have been described to produce their ligninolytic system together with (hemi-) cellulases. For example, the white rot Trametes versicolor expresses genes related to ligninolytic and (hemi)-cellulolytic activity in a region 15-35 mm from the colony hyphal front (Presley et al., 2018; Zhang et al., 2019). The white rots Phanerochaete chrysosporium and Stereum hirsutum have a delayed onset of ligninolytic activities (Moukha et al., 1993; Korripally et al., 2015; Presley et al., 2018) and expression of (hemi-) cellulolytic genes in $P$. chrysosporium occurs in both younger and older mycelium (Korripally et al., 2015). In contrast, Pleurotus ostreatus separates the bulk of (hemi-) cellulases from its ligninolytic system by producing (hemi-) cellulases $15-20 \mathrm{~mm}$ from its hyphal front while its ligninolytic system is most active in the $0-5 \mathrm{~mm}$ and $30-35 \mathrm{~mm}$ region of its colony (Zhang et al., 2019). Together, white rots show differences in their spatial expression of ligninolytic and (hemi)-cellulolytic activities.

Soil-inhabiting saprotrophs like the litter-decomposer Agaricus bisporus (the white button mushroom) are, like white rots, capable of extensive lignin degradation (Osono, 2007; Jurak et al., 2015). The genomes of litterdegrading and white rot fungi indicate differences in their ligninolytic machinery, possibly relating to the difference in wood and litter environments (Floudas et al., 2020). Yet, the enzymatic system enabling the decomposition of lignin by $A$. bisporus includes MnP and LCC that are thought to play an important role in lignin breakdown by some white rot fungi as well. The expression of CAZYs and their activities throughout the life cycle of Agaricus bisporus have been relatively well studied. This fungus is grown commercially on a horse manure based compost (Grimm and Wösten, 2018) that is produced in two phases. A. bisporus is introduced at the end of Phase II (PII), which starts the vegetative growth period during Phase III (PIII). After topping the PIII-end compost with a casing layer and changing environmental conditions, fruiting is induced (Phase IV [PIV]). It is generally assumed that $A$. bisporus degrades the lignocellulose in the substrate by means of (hemi-) cellulases, LCC and MnP (Bonnen et al., 1994; Patyshakuliyeva et al., 2015). About $40 \%$ of the lignin, $6 \%$ of the xylan (part of the hemicellulose), and $6 \%$ of the cellulose is degraded during PIII relative to PII (Kabel et al., 2017). In addition, a significant part of the microbial population is consumed in
PIII (Vos et al., 2017a,b; Carrasco et al., 2020). Xylan and cellulose are preferentially degraded during PIV with approximately $48 \%$ and $33 \%$ cellulose and xylan being removed after fruiting, respectively, while minor amounts of lignin are removed. The loss of lignocellulose in compost in time is in agreement with overall expression patterns of ligninolytic and (hemi-) cellulolytic genes (Patyshakuliyeva et al., 2015).

So far, physiology and gene expression studies have not been performed at short time intervals during the different phases of the life cycle of $A$. bisporus such as during PIII. Here, we performed such studies, revealing that the expression profile of $A$. bisporus during its vegetative growth is in line with its mycelium cycling through degradation of lignin, degradation of polysaccharides, and uptake of degradation products. This cycling, which is accompanied by respiratory bursts, is synchronized over a large distance within the mycelium and is proposed to enable $A$. bisporus to efficiently degrade litter.

\section{Results}

\section{Respiratory bursts in compost}

The $\mathrm{CO}_{2}$ production and $\mathrm{O}_{2}$ consumption of Pll-end compost inoculated with $A$. bisporus variety Sylvan A15 (A15) was monitored using a respirometer. Noninoculated and sterilized PII-end compost served as a control to exclude the activity of microorganisms other than $A$. bisporus. The $\mathrm{CO}_{2}$ production and $\mathrm{O}_{2}$ consumption were determined every $2.5 \mathrm{~h}$ during a $425 \mathrm{~h}$ measurement period. Measurements started after a 5-days pre-incubation at $25^{\circ} \mathrm{C}$ to allow the $A$. bisporus inoculum to (start to) form an interconnected mycelium. Total $\mathrm{CO}_{2}$ produced per gram of sterile compost, non-inoculated compost, and inoculated compost was 52, 227, and $831 \mu \mathrm{mol}$ during the $425 \mathrm{~h}$ period, respectively (Fig. 1A). The $\mathrm{CO}_{2}$ production rate decreased over time from 1 to $0.3 \mu \mathrm{mol} \mathrm{h}{ }^{-1} \mathrm{~g}^{-1}$ in compost without A. bisporus A15, while $\leq 0.23 \mu \mathrm{mol} \mathrm{CO} \mathrm{CO}_{2} \mathrm{~h}^{-1} \mathrm{~g}^{-1}$ compost was released from sterile compost (Fig. 1B). In contrast, $\mathrm{CO}_{2}$ production in compost with $A$. bisporus $\mathrm{A} 15$ increased from 1.2 to $2.6 \mu \mathrm{mol} \mathrm{h}-1 \mathrm{~g}^{-1}$ substrate during the first $180 \mathrm{~h}$ and then decreased to $1.3 \mu \mathrm{mol} \mathrm{h}^{-1} \mathrm{~g}^{-1}$ compost. This was accompanied by distinct respiratory bursts of $2.5-5 \mathrm{~h}$ (Fig. 1B). The $\mathrm{CO}_{2}$ production rate during the bursts increased up to 3.5 -fold as compared to the intermediate periods. These intermediate periods had an initial length of $13 \mathrm{~h}$ and increased to $20 \mathrm{~h}$. The interval became irregular as illustrated by an increase to $50-90 \mathrm{~h}$ after 200 and $240 \mathrm{~h}$ respectively. No respiratory bursts were observed in the absence of $A$. bisporus A15, but they were produced in sterilized compost inoculated with this fungus (Fig. S1). However, growth of $A$. bisporus A15 in 
A
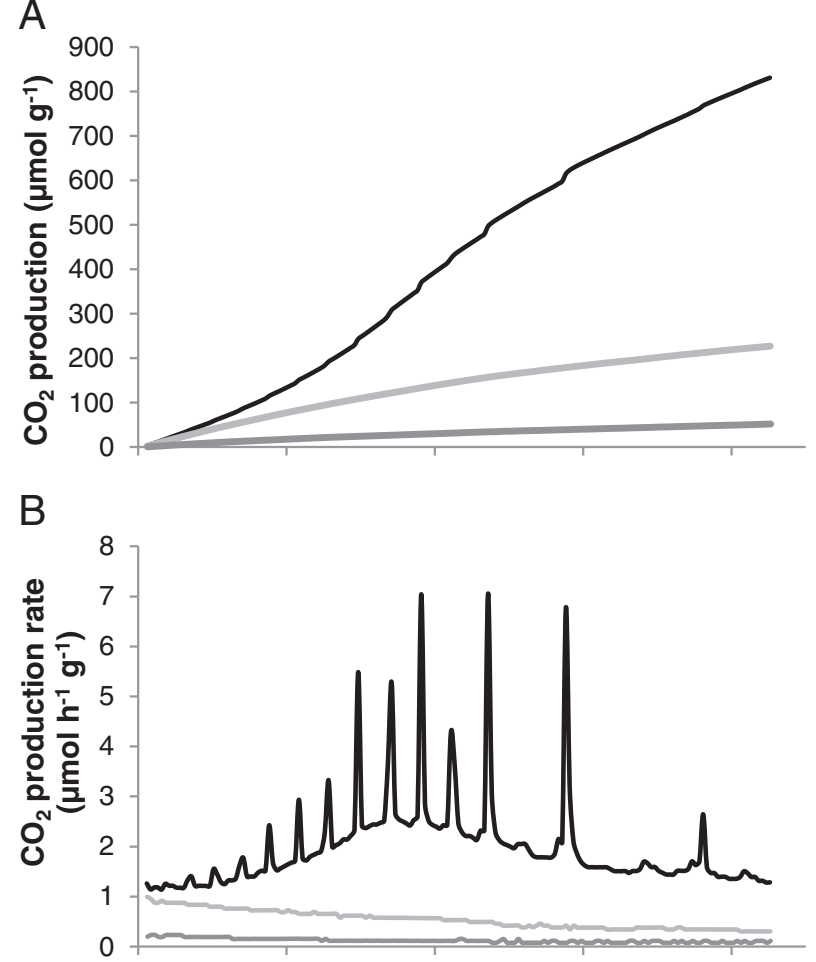

C

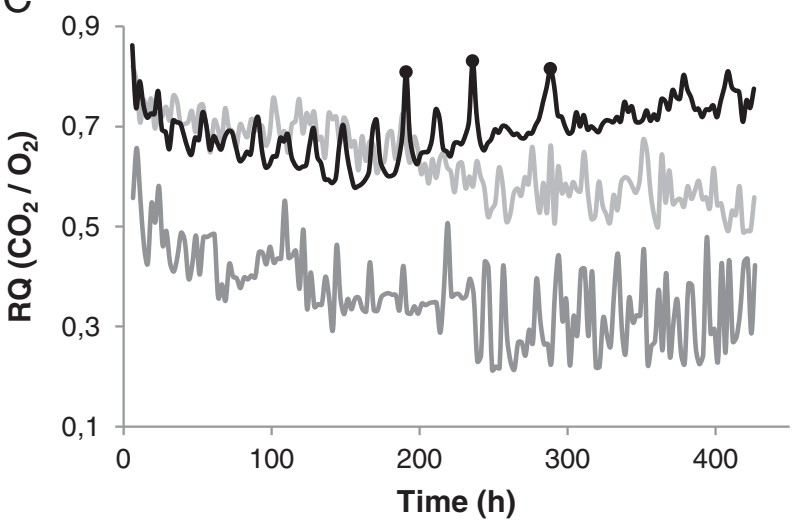

Fig. 1. Cumulative $\mathrm{CO}_{2}$ production $(\mathrm{A}), \mathrm{CO}_{2}$ production rate $(\mathrm{B})$, and respiratory quotient (C) by sterile compost (dark grey), compost without $A$. bisporus (light grey), and compost inoculated with $A$. bisporus (black). $\mathrm{O}_{2}$ levels were below $17.97 \%$ (the limit at which $\mathrm{O}_{2}$ could be measured) at time points indicated with a black dot (C), resulting in an underestimation of the actual $\mathrm{O}_{2}$ consumption and therefore overestimation of the $R Q$.

sterilized compost was slow, likely due to the absence of an active microbiome (Straatsma et al., 1994), coinciding with low $\mathrm{CO}_{2}$ production.

The respiratory quotient $\left(\mathrm{RQ} ; \mathrm{mol} \mathrm{CO}_{2}\right.$ released/mol $\mathrm{O}_{2}$ consumed) in non-inoculated compost decreased from 0.8 to 0.55 during the $450 \mathrm{~h}$ measurement period (Fig. 1C), while it decreased in sterilized compost from 0.6 to 0.3 . In the latter case, this was probably due to a decrease in $\mathrm{CO}_{2}$ release due to abiotic reactions. During the colonization of $A$. bisporus $\mathrm{A} 15$ the maximal $\mathrm{RQ}$ decreased from 0.8 to 0.65 during the first $150 \mathrm{~h}$ period and then increased to 0.8 again in the following $350 \mathrm{~h}$ (Fig. 1C). At three time points, the $\mathrm{O}_{2}$ levels were below $17.9 \%$, the lower limit of detection of the respirometer, resulting in an underestimation of the actual $\mathrm{O}_{2}$ consumption and overestimation of the RQ (Fig. 1C, black dots). The $R Q$ was up to 0.13 higher during bursts as compared to the pre-burst minimum of 0.58 .

$\mathrm{CO}_{2}$ production correlated with an increase in compost temperature. Temperature increase was detected $30 \mathrm{~min}$ after the start of a respiratory burst, peaked $45-90 \mathrm{~min}$ later, and took $2-8 \mathrm{~h}$ to normalize to pre-peak temperature (Supporting Information Fig. S2). Hence, monitoring compost temperature can be used to monitor respiratory bursts. This was adopted to monitor respiratory bursts during PIII and PIV of a semi-commercial A. bisporus A15 cultivation. Respiratory bursts were observed between day 10 and 16 of PIII (Supporting Information Fig. S3) and followed a similar pattern as observed in small-scale lab cultivations. They were also observed during colonization of casing and the first flush but not during the secondflush.

\section{Synchronization of respiratory bursts is mediated by hyphal fusion}

The respiratory bursts observed during colonization of compost by $A$. bisporus A15 are suggestive of synchronized mycelial action in the compost. This synchronization was characterized using six temperature sensors that had been placed $15-25 \mathrm{~cm}$ apart in a $40 \times 60 \mathrm{~cm}$ box containing $8 \mathrm{~kg}$ inoculated Pll-end compost. A. bisporus A15 was allowed to colonize the compost for 8 days at $25^{\circ} \mathrm{C}$ before temperature measurements were started. Respiratory bursts occurred during the first $400 \mathrm{~h}$ of a $700 \mathrm{~h}$ measurement period (Fig. 2A). They resulted in a temperature increase of up to $2^{\circ} \mathrm{C}$ in a $1.5-3 \mathrm{~h}$ period. Different maximum temperatures detected by the different sensors resulted from local differences in the level of colonization by A. bisporus, insulation of the sensor by the compost, and mycelial activity. Initially, the maximum time delay between all sensors measuring a burst was $170 \mathrm{~min}$ (Fig. 2B). This decreased to $50 \mathrm{~min}$ between 33 and $88 \mathrm{~h}$ after the measurements had been started (Fig. 2B), showing that heat production by the mycelium synchronized over at least $50 \mathrm{~cm}$ (the largest distance between the sensors). No pattern was observed in the order sensors measured a burst. The maximum time delay of the sensors picking up a burst increased to $116 \mathrm{~min}$ after a $120 \mathrm{~h}$ measurement period, while after measuring growth for $198 \mathrm{~h}$ not all sensors picked up a burst anymore with one exception at $218 \mathrm{~h}$. After this time point bursts became erratic. 

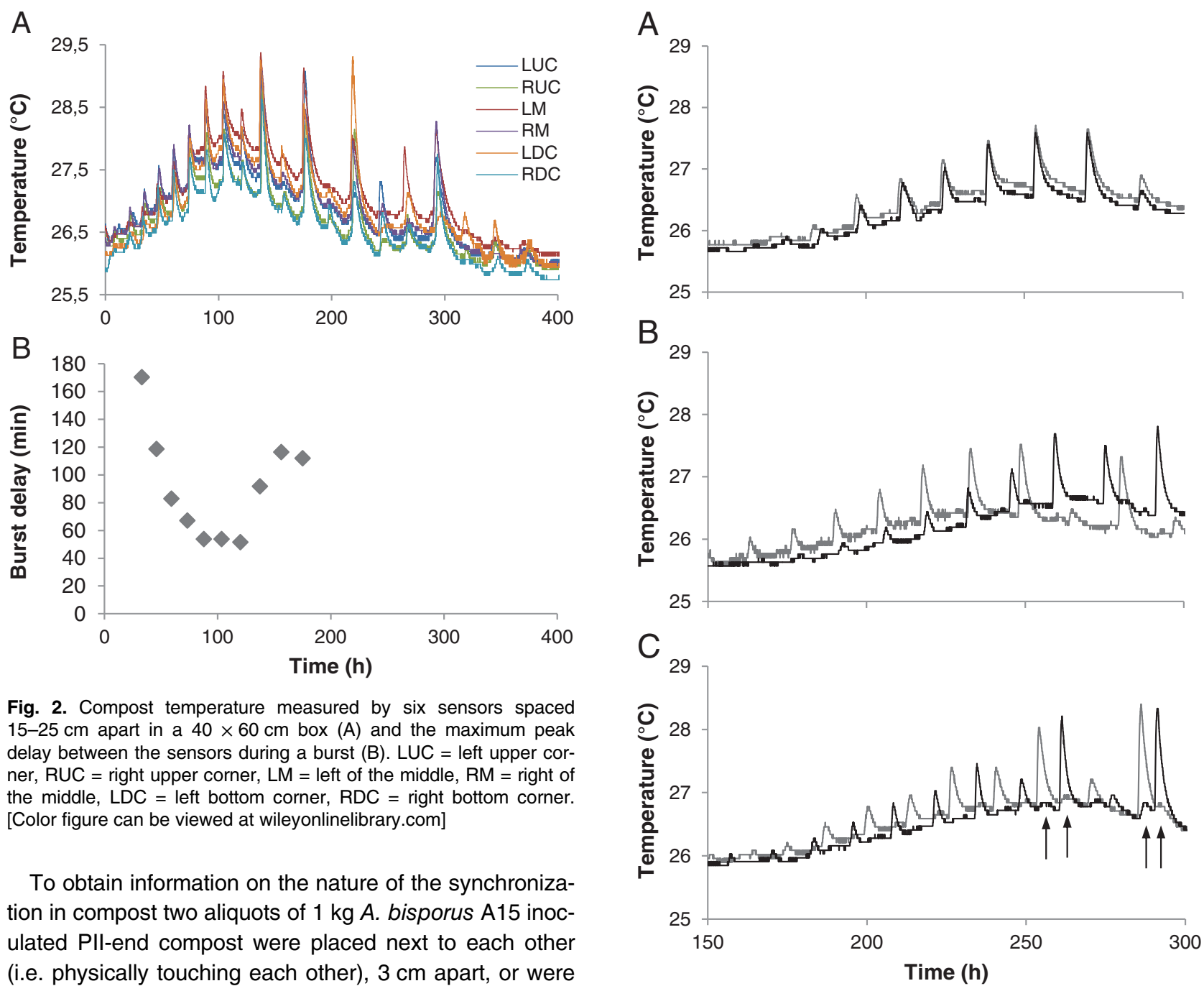

Fig. 2. Compost temperature measured by six sensors spaced $15-25 \mathrm{~cm}$ apart in a $40 \times 60 \mathrm{~cm}$ box (A) and the maximum peak delay between the sensors during a burst $(B)$. LUC = left upper corner, $\mathrm{RUC}=$ right upper corner, $\mathrm{LM}=$ left of the middle, $\mathrm{RM}=$ right of the middle, LDC = left bottom corner, RDC = right bottom corner. [Color figure can be viewed at wileyonlinelibrary.com]

To obtain information on the nature of the synchronization in compost two aliquots of $1 \mathrm{~kg} \mathrm{~A}$. bisporus A15 inoculated PII-end compost were placed next to each other (i.e. physically touching each other), $3 \mathrm{~cm}$ apart, or were separated by aluminium foil. In the latter case, transfer of heat could occur but hyphae of the two parts could not interact. The temperature in the center of both parts of compost was monitored for $300 \mathrm{~h}$ after 8 days of culturing (Fig. 3). The average time between sensors in the two parts of compost picking up a burst was lower when the parts were in physical contact (38 min) when compared to those placed $3 \mathrm{~cm}$ apart or separated by aluminium foil ( $3 \mathrm{~h} 50 \mathrm{~min}$ and $4 \mathrm{~h} 33 \mathrm{~min}$, respectively; Mann-Whitney$\mathrm{U}, P<0.05)$. This suggests that interaction of mycelium is required for the observed synchronization.

Hyphae of $A$. bisporus colonies that are vegetatively compatible can fuse to form a larger colony (O'Connor et al., 2020). The use of two incompatible strains allows to distinguish between proximity of hyphae or hyphal fusion being required for synchronization of bursts over large distances. To this end, compost was divided in four areas of which two were inoculated with $A$. bisporus A15 and two with $A$. bisporus Bisp015 in diagonal positions in a $40 \times 60 \mathrm{~cm}$ box. The mycelium of $A$. bisporus $\mathrm{A} 15$ anastomoses with hyphae of other $A$. bisporus A15

Fig. 3. Typical temperature profiles of two parts of compost (dark and light grey) pressed together (A), placed $3 \mathrm{~cm}$ apart (B), or separated by aluminium foil $(C)$. Arrows indicate where heat transfer through the aluminium foil was detected by the temperature sensor. Each experiment was performed five times. The average difference between two temperature sensors picking up a burst (i.e. the time delay of a burst) for each condition was tested using Mann-Whitney$\mathrm{U}, P<0.05$.

colonies forming a single mycelium (Supporting Information Fig. S4). However, A. bisporus A15 does not anastomose with hyphae of $A$. bisporus Bisp015 as these strains show a vegetative incompatibility, i.e. do not fuse likely due to different alleles in vegetative incompatibility genes (O'Connor et al., 2020; Supporting Information Fig. S4). Temperature sensors placed in an area containing only one of both strains synchronized, while no synchronization of bursts was observed between areas containing A15 and areas containing Bisp015 (Fig. 4A and $B$ ). This shows that anastomosis is required to synchronize the activity of the mycelial colony. 
A

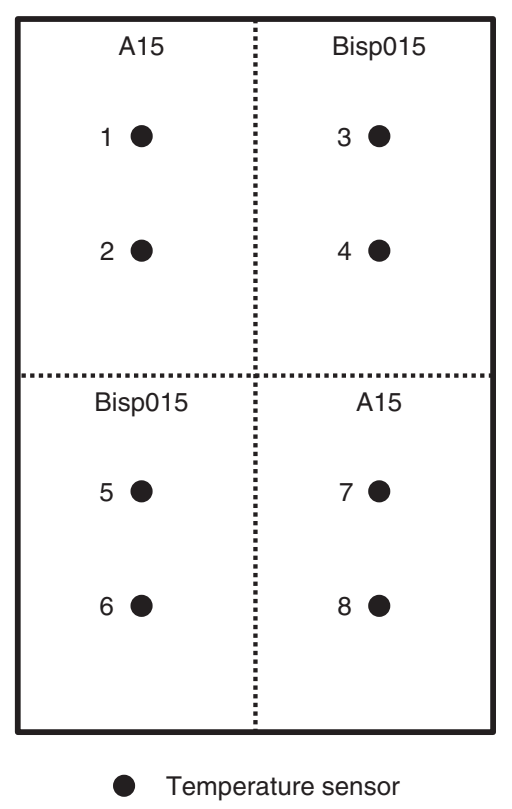

B
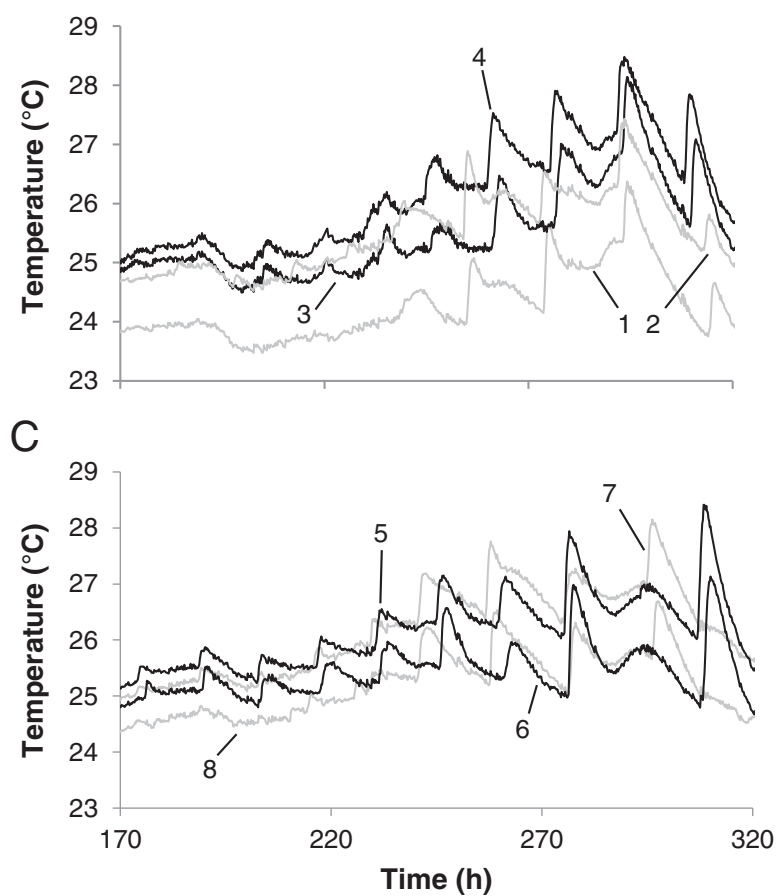

Fig. 4. Experimental setup (A) and typical temperature profile of compost divided in four areas, two of which were inoculated with $A 15$ (B and $C$, black lines) and two with Bisp015 (B and C, grey lines) in diagonal positions in a box. Numbers in panel B and $C$ relate to the location of temperature sensors in panel A. The temperature profiles of A15 and Bisp015 in panel B and C are representative of two independent experiments.

\section{Respiratory bursts occur in sub-peripheral zones of the mycelium}

In all previous experiments, the inoculum of $A$. bisporus was homogeneously distributed throughout the compost. Therefore, it is not possible to distinguish if bursts occur at the hyphal front of a colony or if older parts of the mycelium contribute to these bursts. To distinguish between these options, growth of $A$. bisporus A15 containing PIII compost into fresh PII compost in a square Petri dish was monitored using a flatbed scanner and a temperature sensor. Biomass was distinguished by increased whitening of the compost and the temperature sensor was placed in the middle of the Pll compost to monitor the bursts in a moving hyphal front. The linear growth rate of the hyphal front was $8.8 \mathrm{~mm} \mathrm{~d}^{-1}$. After $163 \mathrm{~h}$ a small temperature increase was observed when the mycelial front had approached the temperature sensor to $8.1 \mathrm{~mm}$ (Fig. 5). This was followed by bursts starting $9 \mathrm{~h}$ after the mycelium had reached the temperature sensor; the hyphal front had grown $3.6 \mathrm{~mm}$ past the sensor at this moment. Bursts were separated by 23-36 h periods. Notably, bursts continued after the mycelial front had passed the probe up to $5.7 \mathrm{~cm}$. At this moment, hardly any biomass was produced anymore at this location as shown by the low increasing of whitening of this area. Moreover, respiratory burst were not accompanied by increased growth as the increase and decrease in grayscale value around bursts was caused by condensation of water and its evaporation. Together, the data indicate that the whole colony of $A$. bisporus (i.e. the hyphal front and older parts of the colony) contribute to the respiratory bursts observed in previous experiments.

\section{Reorganization of gene expression during respiratory bursts}

The physiological characterization of vegetative growth of A. bisporus revealed a burst-like phenomenon not previously observed in fungi growing in complex substrates. RNA was isolated from biological triplicates during, after, and in between bursts $(0.5,4.5$, and $8.5 \mathrm{~h}$ after a burst started respectively) to investigate the process underlying these bursts (Fig. 6A). Out of the 10438 predicted genes encoded by the $A$. bisporus genome, 4731 were differentially expressed (i.e. greater than or equal to twofold upor down-regulated, with an fpkm $>10$ in at least one of the three conditions and a q-value $<0.05$; Fig. $6 \mathrm{~B}$ ). The differentially expressed genes consisted of 1425 genes without annotation, 139 of which encode proteins with a predicted signal sequence for secretion. Differential expression may be a result of de novo RNA synthesis 


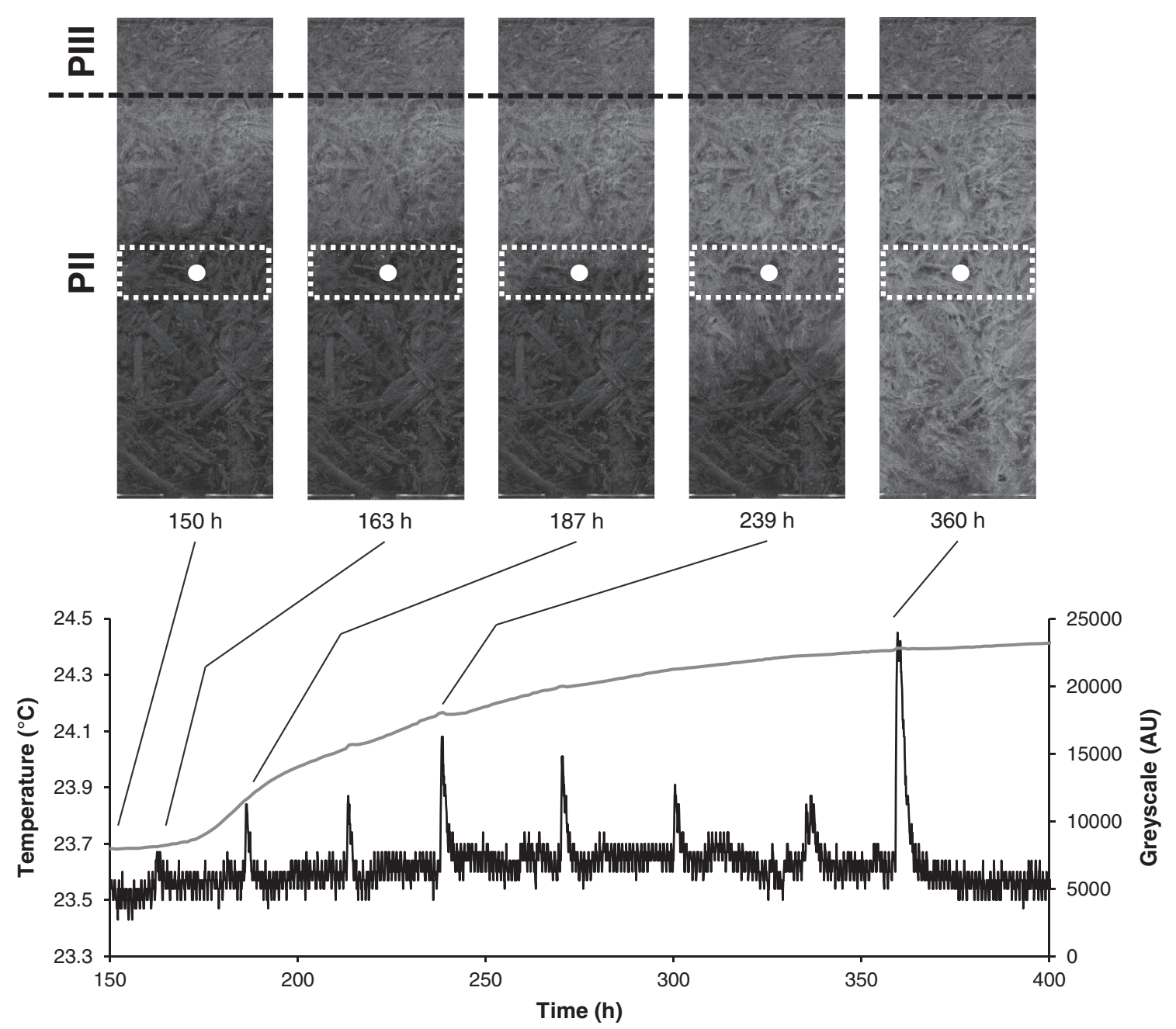

Fig. 5. Compost temperature (black line) and mycelial growth expressed as grey value (grey line, based on the area in the white dashed boxes) during growth of $A$. bisporus from PIII compost into fresh PII compost (border indicated by the dashed line). Scans of the compost after 150, 163, 187,239 , and $360 \mathrm{~h}$ are shown with the position of the temperature sensor indicated (white dot). These data are representative of two independent experiments.

but also of RNA turnover. Therefore, A. bisporus regulation of gene expression during bursts may include degradation of specific transcripts. A total of $197 \mathrm{GO}$ terms and 69 Pfam domains were over- and/or under-represented in sets of up- or down-regulated genes (Supporting Information Dataset S1). Cell cycle (i.e. cell division and/or nuclear division) and translation-related GO terms were overrepresented and underrepresented, respectively, in upregulated genes after a burst relative to during a burst, while GO terms related to transcription and the cell membrane were overrepresented in genes upregulated after a burst when compared to the other two samples. The GO term related to metabolic processes was overrepresented in genes upregulated during the bursts relative to the inter-burst samples and in downregulated genes after a burst relative to the other two samples. Furthermore, cell wall-related GO terms were overrepresented in genes downregulated during a burst when compared to the inter-burst samples. Proteins with a predicted secretion signal were overrepresented in both upregulated and downregulated genes during a burst compared to the inter-burst samples. In addition, these proteins were overrepresented in downregulated genes after a burst relative to the other two samples. The differential expression of cyclins after a burst points to a synchronized cell cycle (Supporting Information Text S2). It is not clear which functions these cyclins have; i.e. whether they are involved in nuclear division or in growth.

Expression of CAZYs and proteases was increased during a burst, while enzymes with a potential role in metabolism of lignin derived products ( $\mathrm{P} 450$, Hemethiolate peroxygenase [HTP], $\beta$-etherase), and sugar, amino acid, and other transporters were highly expressed after a burst (Fig. 6C). Putative sugar transporter genes 
A

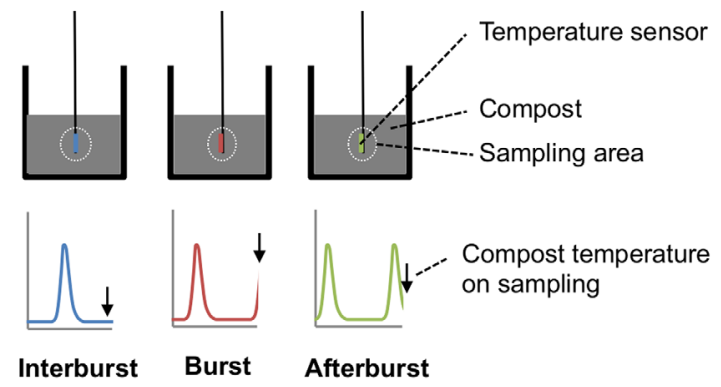

C

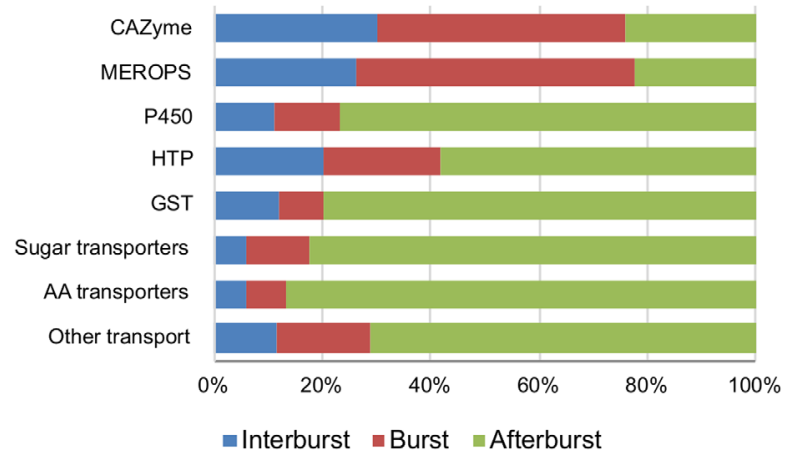

B Upregulated genes

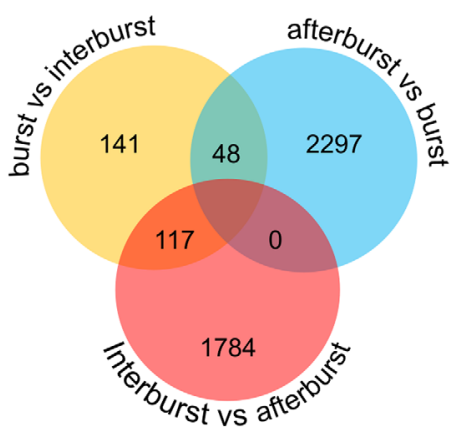

Downregulated genes

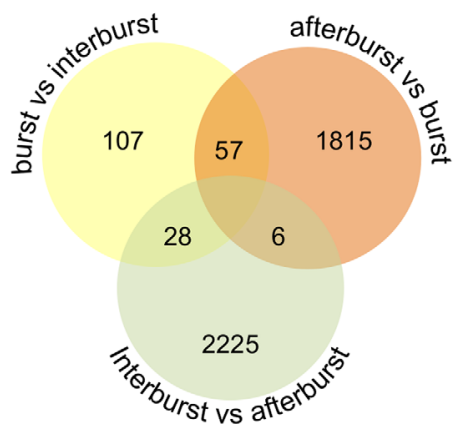

Fig. 6. Schematic representation of experimental setup for the transcriptome analysis of respiratory bursts (A) and analysis of differentially expressed genes. Samples were harvested in between bursts (end of blue line), during bursts (end of red line), or after a burst (end of green line). For each point, RNA was isolated from three biological replicates. Up- (B, top panel) and down- (B, lower panel) regulated genes before a burst, during a burst, and after a burst (i.e. greater than or equal to twofold up or downregulated, with an $\mathrm{fpkm}>10$ in at least one of the three conditions and a q-value < 0.05). Relative abundance of FPKM of differentially expressed genes annotated as CAZYs, MEROPS proteases, P450 enzymes, heme-thiolate peroxidases (HTP), gluthatione-S-transferase (GST), sugar transporters, amino acid transporters, and other transporters (C). [Color figure can be viewed at wileyonlinelibrary.com]

(Pfam 00083) were overrepresented in the downregulated genes during the inter-burst relative to after a burst (Supporting Information Dataset S1). Indeed, the majority of differentially expressed sugar transporters were upregulated after a burst (Fig. 6C; Supporting Information Dataset S7; 19 out of 33). In addition, differentially expressed amino acid/peptide transporter genes were mostly upregulated after a burst (20 out 26; Fig. 6C; Supporting Information Dataset S7; Pfam 03169, 00854, 01490, 00324, and 13520). From the remaining 50 differentially expressed transporter genes (annotated with Pfam 07690; Fig. 6C; Supporting Information Dataset S7) 36 were upregulated after a burst. These genes included putative nicotinic acid and thiamine transporter genes and transporter genes putatively involved in secretion of toxins (Pfam 06609; Alexander et al., 1999). The combination of transporters and secreted proteins being differentially expressed points to changes in the extracellular availability of free sugars. Therefore, the CAZYs were analysed in more detail. Expression values of each differentially expressed CAZY family were summed to identify general patterns in their expression (Fig. 7). The number of differentially regulated genes in each CAZY class can be found in the figure description.

\section{Downregulation of the ligninolytic system after bursts}

$\mathrm{MnPs}$ and LCCs (AA2 and AA1_1) were highly expressed before and during bursts but downregulated up to 367-fold for the most highly expressed LCCs after bursts (Fig. 7A; Supporting Information Dataset S2 and S3). Similarly, glyoxal oxidases (GLOX; AA5_1) and alcohol oxidases (AO; AA3_3) were downregulated (3.5- to 194-fold) after a burst and upregulated 2.3- to 58-fold in between bursts. Putative aryl alcohol oxidases, glucose 1-oxidases, and pyranose dehydrogenases (AA3_2) were upregulated after a burst and downregulated in the interburst samples. Expression of fatty acid desaturases (Protein ID 194591 and 193825; Supporting Information Dataset S4) peaked after a burst, being upregulated 13.6- to 243-fold compared to a burst and the inter-burst. These data show that genes encoding the ligninolytic machinery are actively expressed before and during 
A

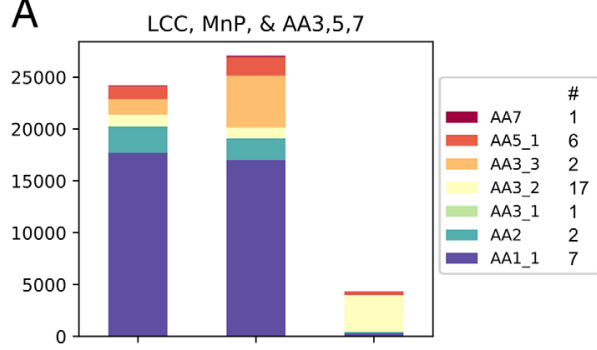

C

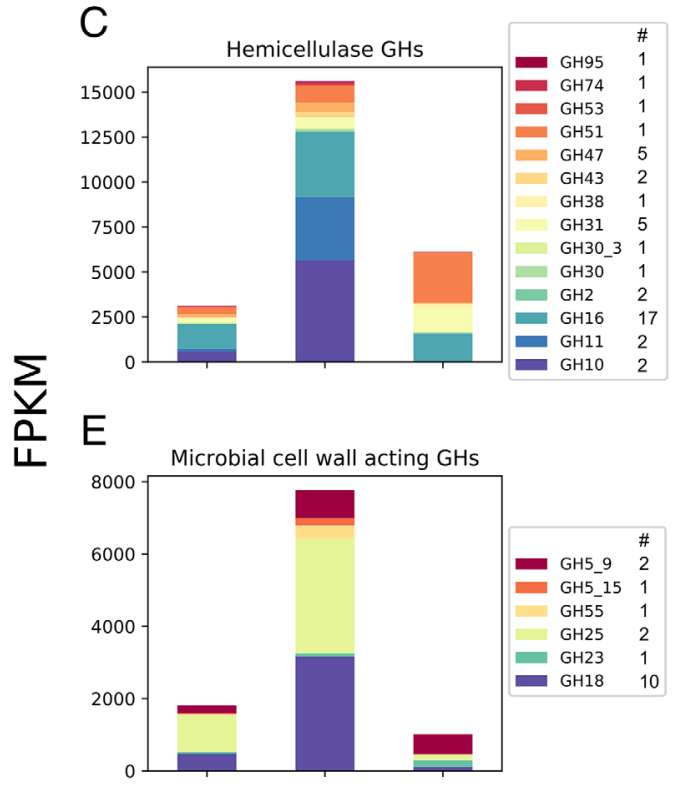

B

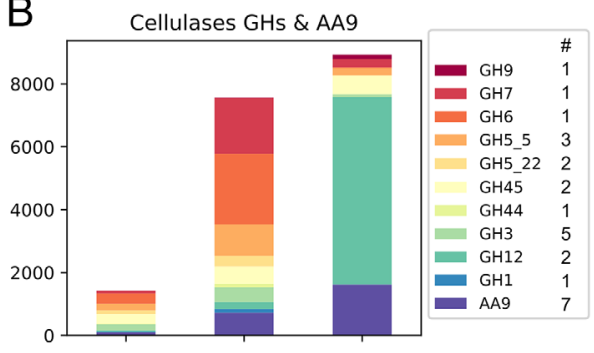

D

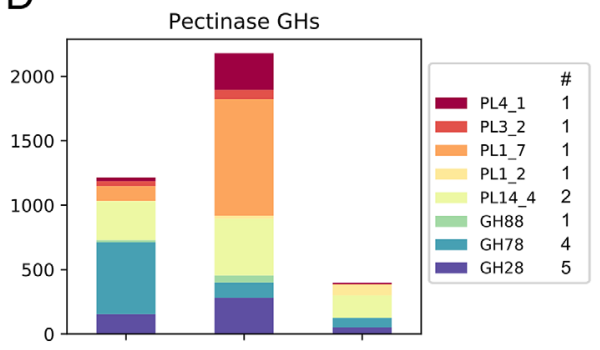

$\mathrm{F}$

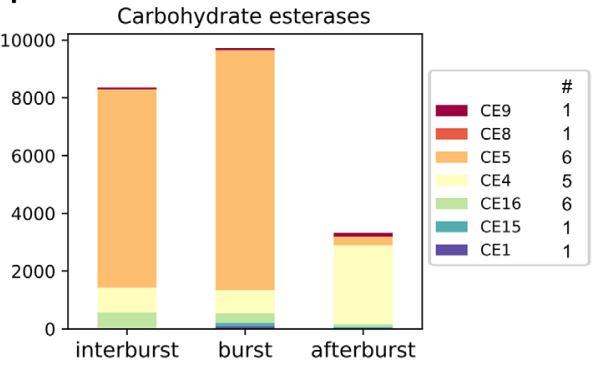

G

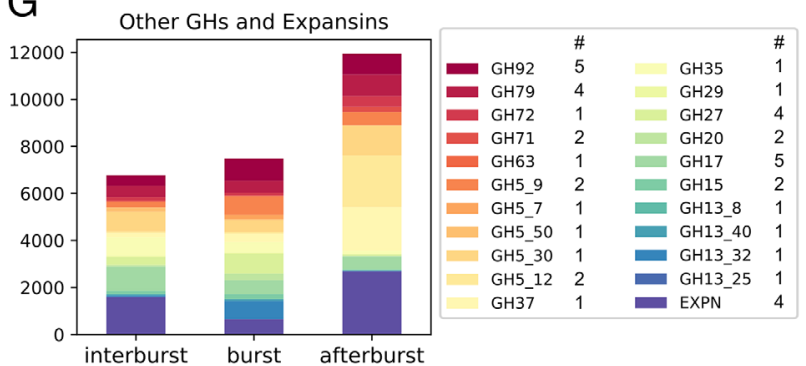

Fig. 7. Expression values (FPKM) of differentially expressed classes of CAZYs related to lignin degradation (A), cellulose degradation (B), hemicellulose degradation $(C)$, pectin degradation $(D)$, microbial cell wall degradation and remodelling $(E)$, carbohydrate esterases $(F)$, other $G H s$ and expansins (G). Bars represent expression values before (inter-burst) during (burst) and after bursts (after burst). The number of differentially expressed genes that are considered for each CAZY class are listed in the legenda of each subfigure. [Color figure can be viewed at wileyonlinelibrary.com]

bursts, while they are downregulated after bursts with the exception of fatty acid desaturases.

\section{Polysaccharide deconstruction $C A Z Y$ s are upregulated during respiratory bursts}

Cellulase genes (Fig. 7B; Supporting Information Dataset S2 and S3) were upregulated during and after bursts relative to in between bursts. Putative endo- and exo-acting cellulases like GH5_5, GH6, GH7, GH45, and the LPMO AA9 dominated the expression of cellulases during bursts while the endoglucanase $\mathrm{GH} 12$ genes together with AA9 and $\mathrm{GH} 45$ were dominantly expressed after bursts. Hemicellulases peaked in expression during bursts and were dominated by putative endo-acting hemicellulases like $\mathrm{GH} 10, \mathrm{GH} 11$, and $\mathrm{GH} 16$ while after bursts GH16, GH31, and GH51 were dominantly expressed (Fig. 7C). Similar to the ligninolytic system pectinases were downregulated after bursts (Fig. 7D). In between bursts, the GH78 and the PL14_4 pectinase 
families were dominantly expressed, while the PL4_1, PL1_7, PL14_4, and GH28 pectinase families were most highly expressed during bursts. Glycoside hydrolase families acting on microbial cell walls were upregulated during bursts (Fig. 7E) and their expression was dominated by lysozyme and chitinase families $\mathrm{GH} 18$ and $\mathrm{GH} 25$, and putative $\beta$-1,3-glucanases and $\beta$-1,6-glucanases (GH5_9, GH5_15, and GH55). Putative cutinases of the carbohydrate esterase family CE5 were dominantly expressed in between and during bursts (Fig. 7F; Supporting Information Dataset S2 and S3). The CE5 family was downregulated after bursts, while the putative chitin deacetylases of the CE4 family were upregulated after a burst. Finally, expression of expansins was lower during bursts compared to the samples in between and after bursts (Fig. 7G). From these data, it is clear that genes involved in degradation of hemicellulose and microbial cell walls are primarily expressed during bursts while cellulases are also expresses after a burst.

Sets of protease genes are upregulated during and after respiratory bursts and in inter-burst periods

Upregulation of amino acid and peptide transporters after bursts point to increased extracellular availability of these nutrients at this stage. MEROPS protease genes were enriched in the upregulated genes during a burst, in the downregulated genes after a burst and the upregulated genes during the inter-burst (Supporting Information Dataset S1). Specifically, sets of protease genes were expressed during, after and in between bursts (Supporting Information Dataset S5). For example, 19 out of 23 and 49 out of 54 protease genes upregulated during and after a burst, respectively, were most highly expressed at that sample point. The highly expressed serine protease gene SRP1 (Burton et al., 1997; Heneghan et al., 2016) (Protein ID 194648) that is implicated in nitrogen acquisition from humic-rich substrates was upregulated 3.5-fold during a burst and 372-fold downregulated after this event. Together, this suggests a highly differentiated role for proteases in vegetative growth of $A$. bisporus.

\section{Expression of metabolic genes support a repeated} reorganization of fungal metabolism

A total of 15 out of 59 genes involved in glycolysis, the pentose phosphate pathway (including genes involved in conversion of pentoses to D-xylulose), and the galactose pathway changed expression more than fivefold during cycling (Supporting Information Dataset S8). For example, the pyruvate kinase (EC 2.7.1.40), ribose-phosphate pyrophosphokinase (EC 2.7.6.1) and ribulose-phosphate 3-epimerase (EC 5.1.3.1) genes were upregulated 37-,
10-, and 16-fold after a burst respectively. Furthermore, 7 out of 21 genes involved in the TCA cycle changed expression greater than or equal to fivefold of which four were downregulated after a burst and two were upregulated after a burst. A predicted trehalose phosphorylase (EC 2.4.1.231/2.4.1.64) and mannitol1-phosphate dehydrogenase (EC 1.1.1.17) gene were upregulated 3.8- and 13-fold, respectively, after a burst. This indicates that the metabolism of $A$. bisporus is regulated in a cyclic way during most of the vegetative growth in compost.

The secreted oxalate decarboxylase (Kathiara et al., 2000; EC 4.1.1.2) and intracellular formate dehydrogenase (EC 1.17.1.9) genes were downregulated 5.3and 105-fold, respectively, after a burst and stably expressed in between and during bursts. Two glyoxalase genes (Pfam 00903) and a putative glyoxylate reductase gene (EC 1.1.1.26) were also downregulated after a burst (5.6- to 39-fold), while the putative glyoxylate reductase gene and a glyoxalase gene were upregulated before and during a burst (2.3- to 17.9-fold and 2.2- to 2.5-fold, respectively). This shows that genes involved in oxalate metabolism are downregulated after bursts.

\section{Discussion}

Growth of filamentous fungi in complex substrates is associated with respiration (i.e. production of $\mathrm{CO}_{2}$ and $\mathrm{O}_{2}$ consumption) and heat production, yet these variables are rarely measured. Here, a respirometer and temperature electrodes were used to study the vegetative growth of $A$. bisporus in compost revealing bursts of temperature and respiratory activity. Respiratory cycles with periods varying between 7.5 and $22.5 \mathrm{~h}$ (i.e. distinct from a circadian type of rhythm) have been observed during colonization of malt extract and wood blocks by the brown rot fungi Neolentinus suffrutescens (Lentinus lepideus), Gloeophyllum trabeum (Lenzites trabea), Postia placenta (Poria monticola), and Coniophora puteana (Damaschke and Becker, 1966; Smith, 1973). This indicates that respiratory patterns are widespread in basidiomycetes. However, the increase in respiration during bursts produced by $A$. bisporus is more dramatic (up to 3.5 -fold) compared with the wave-like respiratory patterns of brown rot fungi (up to 0.3-fold). Bursts of $A$. bisporus became increasingly synchronized over a distance of at least $50 \mathrm{~cm}$ and required anastomosis of hyphae as the burst produced by incompatible strains A15 and Bisp015 did not synchronize. The loss of synchronization in late vegetative growth of A15 may reflect loss of mycelial interactions, possibly due to lysis of hyphae. Older parts of the mycelium participated in bursts as they were observed until the outer region of the mycelium had passed the temperature sensor $5.7 \mathrm{~cm}$. Thereafter, the mycelium 
had reached the edge of its substrate and bursts were no longer observed. Growth of the hyphal front may, therefore, be important for the occurrence of bursts in older parts of the mycelium.

Compost temperature increased up to $2^{\circ} \mathrm{C}$ in 1.5 to $2 \mathrm{~h}$ during bursts corresponding to the release of up to $5 \mathrm{~kJ}$ energy $\mathrm{kg}^{-1}$ compost when assuming a water content of $60 \%$. Thornton's Rule shows that $\mathrm{O}_{2}$ consumption can fully explain the temperature increase observed in compost (Thornton, 1917; Hansen et al., 2004; Supporting Information text S3; Tables S1 and S2). The decrease in $\mathrm{RQ}$ from 0.8 to 0.65 in the period where respiratory bursts are most regular (Fig. 1C, first $150 \mathrm{~h}$ ) fits with the formation of oxidized compounds like oxalic acid that are formed around hyphae of $A$. bisporus during its vegetative growth (Atkey and Wood, 1983) and preferential lignin mineralization during PIII (Kabel et al., 2017). Lignin mineralization accounts for approximately $84 \%$ of the total heat production during PIII (Supporting Information text S3; Tables S3, S4), while the total $\mathrm{O}_{2}$ consumption during bursts is $21 \%$ of total $\mathrm{O}_{2}$ consumption (Supporting Information Table S1). Therefore, lignin degradation cannot occur solely in bursts as oxygen consumption does not match what is expected from lignin loss.

Transcriptomic data, obtained in between, during, and after bursts, supports the view that $A$. bisporus cycles through degradation of lignin, (hemi-) cellulose and microbial biomass, and uptake of breakdown products using a synchronized vegetative growing mycelium. The ligninolytic system of $A$. bisporus is active before and during these bursts while (hemi-) cellulolytic genes and genes encoding microbial biomass degrading activities are upregulated during and after this event. The active expression of sugar and amino acid transporters after a burst indicates that carbon influx occurs at this time whereafter nutrients are likely redistributed throughout the mycelial network (Herman et al., 2020). Indeed, genes involved in glycolysis and the pentose phosphate pathway were upregulated (up to 37 -fold) after a burst. In addition, expression of trehalose phosphorylase and mannitol-1-phosphate dehydrogenase genes was increased after bursts too (up to 13-fold). Therefore, trehalose and mannitol may not only play a role in mushroom formation (Hammond and Nichols, 1976) but also in carbon storage and transport within the mycelial network.

The increase in respiration and the oscillations of the $R Q$ around the time bursts occur (e.g. from 0.58 to 0.71 ) show that there is increased mineralization of more oxidized substrates during a burst. This could be explained by the consumption of sugars $(R Q=1)$ but also mineralization of oxalic acid $(R Q=4)$. This link between bursts and oxalate metabolism is supported by downregulation of putatively secreted oxalate decarboxylase and formate dehydrogenase after bursts (up to 105-fold). Thus, the bursts and $R Q$ oscillations could relate to mineralization of extracellular oxalic acid. Free energy conservation in oxalate (or sugar) metabolism produces ATP that would be required for synthesis of secreted proteins like CAZYs during bursts. Protein production is an energy intensive process (Stouthamer, 1973). Hence, protein synthesis could partly explain the temperature increase $\left(\mathrm{O}_{2}\right.$ consumption) during bursts. Protein secretion could be facilitated by formation of new (small) branching hyphae or cell wall remodelling of older mycelium (Wosten et al., 1991; Krijgsheld et al., 2013). Furthermore, a burst was observed in the first flush of a semi-commercial cultivation but not in the second flush. Possibly relating to previous observations where low expression of CAZYs was found in samples taken during the second flush (Patyshakuliyeva et al., 2015).

In line with downregulation of the ligninolytic system, $\mathrm{MnP}$, LCC, glyoxal oxidases, and alcohol oxidase genes were downregulated up to 194-fold after a burst together with oxalate metabolism. This fits with degradation of lignin (and humic compounds) before and during bursts, where ligninolytic action of a synchronized mycelium increases accessibility of carbohydrates together with pectinase and cutinase genes. As with white rot fungi, ligninolytic action of $A$. bisporus should include the production of extracellular radical species. Indeed, there is evidence for radical generation by $A$. bisporus in compost based on the presence and generation of $\mathrm{H}_{2} \mathrm{O}_{2}$ in compost water extracts (Savoie et al., 2007; Vos et al., 2017a,b). In addition, components involved in Fenton chemistry, like $\mathrm{Fe}^{2+}$ and $\mathrm{H}_{2} \mathrm{O}_{2}$, but also molecules that are required for extracellular lipid peroxidation, e.g. unsaturated lipids, glyoxal oxidase, and $\mathrm{MnP}$, are presumably present in compost. Analysis of iron-species and experiments with 14/13C-labelled lignin or fatty acids combined with pyrolysis-GC-MS and NMR (Wood, 1983; Van Erven et al., 2019) may provide insights in the chemistry of lignin and humic acids degradation by A. bisporus. These insights may pave the road in understanding the radical chemistry employed by this fungus in situ (i.e. a role of Fenton chemistry and/or lipid peroxidation) during its cultivation process as well as during bursts. Recent insights in the decay strategy of brown rot fungi points to the production of hydroxyl radicals by their hyphal front while the bulk of (hemi-) cellulases is produced by older mycelium (Zhang et al., 2016, 2019; Presley and Schilling, 2017; Castaño et al., 2018). $\mathrm{H}_{2} \mathrm{O}_{2}$ and other radical species can damage proteins involved in polysaccharide deconstruction and spatial separation of radical generation and (hemi-) cellulases can protect these CAZYs from oxidative damage (Zhang et al., 2016; Castaño et al., 2018). In addition, the pre-treatment of plant cell walls with Fenton chemistry derived radicals or a ligninolytic system allows a more efficient (hemi-) 
cellulose deconstruction by CAZYs (ten Have et al., 2003; Arantes et al., 2012). Therefore, temporal cycling in ligninolytic and cellulolytic activities by A. bisporus may enable the repeated pre-treatment of compost and protect extracellular proteins from radical species, resulting in a more efficient substrate decomposition when compared to a spatial separation of ligninolytic and cellulolytic activities.

\section{Material and methods}

\section{Strain and growth conditions}

A. bisporus strains $\mathrm{A} 15$ (Sylvan, the Netherlands) and Bisp015 were grown in PII-end compost (CNC Grondstoffen, Milsbeek, the Netherlands) at $25^{\circ} \mathrm{C}$ unless otherwise indicated. Compost was inoculated with either rye based A15 (Gift from CNC Grondstoffen) or Bisp015 spawn (Basidiomycete culture collection WUR, Wageningen, the Netherlands) or with PIII compost. Respiration measurements were done in $1 \mathrm{I}$ bottles using $50 \mathrm{~g}$ Pll-end compost that was either or not inoculated with 10 spawn grains. Temperature was monitored either in boxes or in square Petri dishes. In the latter case, square Petri dishes $(12 \times 12 \times 1.2)$ were filled with $57.6 \mathrm{~g}$ PII compost on one side and $11.5 \mathrm{~g}$ PIII compost on the other side from which the PII compost was colonized. Growth in boxes was done using $1 \mathrm{~kg}(30 \times 20 \times 22 \mathrm{~cm}$ boxes $)$, $8 \mathrm{~kg}(40 \times 60 \times 20 \mathrm{~cm}$ boxes $)$, or $16 \mathrm{~kg}(40 \times 60 \times 22 \mathrm{~cm}$ boxes) PII-end compost that was inoculated with 8,64 , or $75 \mathrm{~g}$ of spawn respectively. The 1 and $8 \mathrm{~kg}$ compost boxes that were used to monitor temperature dynamics during PIII were covered with plastic film containing 50 3-mm-wide holes $\mathrm{m}^{-2}$. The $16 \mathrm{~kg}$ compost boxes were used to monitor temperature dynamics both during PIII and PIV under cultivation conditions described previously (Vos et al., 2017a,b).

\section{Quantification of $\mathrm{CO}_{2}, \mathrm{O}_{2}$, temperature and growth}

Correlation of $\mathrm{CO}_{2}$ production and $\mathrm{O}_{2}$ consumption was done using a respirometer (Biometric Systems, Germany) with optical $\mathrm{CO}_{2}$ and $\mathrm{O}_{2}$ sensors. In short, $\mathrm{CO}_{2}$ and $\mathrm{O}_{2}$ was measured using biological triplicates at $\mathrm{t}=0$ and $\mathrm{t}=2.5 \mathrm{~h}$, after which the air in the flask was refreshed. This was repeated 170 times during a $425 \mathrm{~h}$ period. Data were converted to molar amounts of produced $\mathrm{CO}_{2}$ and consumed $\mathrm{O}_{2}$, correcting for temperature and pressure.

Growth in compost was measured by placing $12-\mathrm{cm}-$ square Petri dishes in a flatbed scanner (Epson V300/ V370, Seiko Epson Corporation, Shinjuku, Tokyo, Japan). Compost was scanned every hour. These images were produced in 16-bit grayscale intensity at 2400 dpi resolution (10.6 $\mu \mathrm{m}$ pixel size). The grey values were quantified in a $3.8 \times 0.5 \mathrm{~cm}$ window around a Pt100 (class B) temperature sensor probe $(1.83 \times 6 \mathrm{~mm}$; Sensing Devices LLC, Lancaster, USA) that had been placed inside the $2 \mathrm{~cm}$ layer PII compost in the middle of the square Petri dish before placing the dish in the scanner. Temperature was logged by connecting the temperature probe to a real-time clock (RTC) DS1307 module, a micro-SD module, a MAX31865 RTD module, and an Arduino Nano according to manufacturer's instructions. Temperature was measured every $5 \mathrm{~min}$, while the mean grayscale intensity within the temperature probe area was quantified over time using ImageJ. The scanner was covered with a $5 \mathrm{~cm}$ thick walled polystyrene box to minimize the effect of the incubator hysteresis.

Arduinos (https://www.arduino.cc/) equipped with temperature (DS18B20; Dallas Semiconductor, USA) or $\mathrm{CO}_{2}$ (MG811; Sandbox Electronics, Finland) sensors were used to measure and correlate changes in temperature and $\mathrm{CO}_{2}$ levels in box experiments. To this end, the temperature sensor was placed $2 \mathrm{~cm}$ below the compost surface, while the $\mathrm{CO}_{2}$ sensor was placed $5 \mathrm{~cm}$ above the compost.

Vegetative incompatible strains (A15/Bisp015) and vegetative compatible strains (A15/A15 and Bisp015/ Bisp015) were grown together in duplo in a $40 \times 60 \mathrm{~cm}$ compost box filled with $16 \mathrm{~kg}$ compost. The compost was divided in four areas, two of which were inoculated with A15 and two with Bisp015 in diagonal positions. Two thermocouple probes (Type $\mathrm{T}$; Copper/Constantan) were placed per separate area (eight probes in total). Temperature changes were recorded using a DT85 Series 2 Data logger (Cambeep, Cambridge, United Kingdom), every 10 min starting on day 1 of cultivation and ending at day 18.

\section{RNA isolation}

RNA was isolated from $7.5 \mathrm{~g}$ colonized compost of box cultures $(30 \times 20 \times 22 \mathrm{~cm})$ after $130-145 \mathrm{~h}$ of incubation (Supporting Information Fig. S5). Samples (biological triplicates) were taken from the immediate surroundings of a temperature sensor during and after a burst and in between bursts (i.e., 0.5, 4.5, and $8.5 \mathrm{~h}$ after a burst started respectively). Compost was crushed using mortar and pestle under liquid nitrogen and ground to a fine powder for $1 \mathrm{~min}$ at $30 \mathrm{~Hz}$ using a tissuelyser II with a steel grinding jar pre-cooled with liquid nitrogen (Qiagen, Venlo, the Netherlands). RNA was extracted using a modified method described by Patyshakuliyeva et al. (2014). For each sample, $200 \mathrm{mg}$ compost powder was transferred to $7 \mathrm{ml}$ extraction buffer (4 $\mathrm{M}$ guanidinium thiocyanate, $25 \mathrm{mM}$ sodium citrate, $\mathrm{pH} 5.0$, $0.5 \% \mathrm{~N}$-lauroyl sarcosine, $0.1 \mathrm{M} \beta$-mercaptoethanol), shaken vigorously, and incubated for $10 \mathrm{~min}$ at RT. Next, 
$7 \mathrm{ml}$ of chloroform:isoamyl alcohol (24:1) was added, mixed by vortexing, and incubated for $2 \mathrm{~min}$. Phases were separated by centrifugation for $15 \mathrm{~min}$ at $4500 \mathrm{~g}$ and $6.5 \mathrm{ml}$ of the aqueous phase was transferred to an ultracentrifugation tube (Ultra-Clear, open-top; Beckman coulter) filled with a $2 \mathrm{ml}$ cushion of $5.7 \mathrm{M} \mathrm{CsCl}$ in $25 \mathrm{mM}$ sodium citrate, $\mathrm{pH}$ 5.0. The tube was topped with $7 \mathrm{ml}$ $0.8 \mathrm{M}$ guanidine thiocyanate, $0.4 \mathrm{M}$ ammonium thiocyanate, $0.1 \mathrm{M}$ sodium acetate, $\mathrm{pH} 5$ (TS buffer). RNA was pelleted by centrifugation for $24 \mathrm{~h}$ at $4^{\circ} \mathrm{C}$ and $104.000 \mathrm{~g}$ in a SW28.1 swing out rotor (Beckman Coulter, Brea, CA, USA). RNA was taken up in $100 \mu \mathrm{l} \mathrm{H}_{2} \mathrm{O}$ and $500 \mu \mathrm{l}$ TS buffer was added. RNA was precipitated with 0.8 volume isopropanol, washed with $70 \%$ ethanol, and further purified using a Qiagen RNeasy Mini Kit. RNA quality and quantity was assessed using gel electrophoresis and a Qubit Fluorometer.

\section{RNA sequencing and analysis}

Strand-specific mRNA-seq libraries for the Illumina platform were generated and sequenced at BaseClear BV (Leiden, The Netherlands). High-quality total RNA (checked and quantified using a Bioanalyzer; Agilent, Santa Clara, CA, USA) was used as input for a dUTP library preparation method (Parkhomchuk et al., 2009; Levin et al., 2010). For dUTP library preparation, the mRNA fraction was purified from total RNA by polyA capture, fragmented and subjected to first-strand cDNA synthesis with random hexamers in the presence of actinomycin D. The second-strand synthesis was performed incorporating dUTP instead of dTTP. Barcoded DNA adapters were ligated to both ends of the doublestranded CDNA and subjected to PCR amplification. The resulting library was quality checked and quantified using a Bioanalyzer (Agilent). The libraries were multiplexed, clustered, and sequenced on an Illumina HiSeq 2500 (HiSeq Rapid SBS v2 chemistry) with a single-read 50 cycles sequencing protocol and indexing. At least 10 million $50 \mathrm{bp}$ single reads were generated per sample.

FASTQ sequence files were generated using bcl2fastq2 version 2.18. Initial quality assessment was based on data passing the Illumina Chastity filtering. Subsequently, reads containing PhiX control signal were removed using an in-house filtering protocol. In addition, reads containing (partial) adapters were clipped up to minimum read length of $50 \mathrm{bp}$. Remaining reads were subjected to a second quality assessment using the FASTQC quality control tool version 0.11 .5 (http:// www.bioinformatics.babraham.ac.uk/projects/fastqc/) and deposited in NCBI GEO with accession number GSE124976. HISAT version 2.1.0 (Kim et al., 2015) was used to align sequence reads to the Agabi_varbisH97_2 version of the $A$. bisporus H97 genome (Morin et al., 2012; Sonnenberg et al., 2020), which was obtained from MycoCosm (Grigoriev et al., 2014). Cuffdiff (version 2.2.1), which is part of Cufflinks (Trapnell et al., 2010), was used to identify reads mapping to predicted genes and to identify differentially expressed genes. The bias correction method was used while running Cuffdiff (Roberts et al., 2011). Cuffdiff normalizes the expression level of each predicted gene to fragments per kilobase of exon model per million fragments (FPKM). In addition to Cuffdiff's requirements for differential expression the following requirements were applied: $a \geq$ twofold change and a minimal expression level of 10 FPKM in at least one of the samples. Therefore, genes with an fpkm $<10$ in a sample point were only included in the set of differentially expressed genes when meeting the aforementioned conditions in another sample point. Quality of these results was analysed using CummeRbund (Goff et al., 2013). All expression data can be found in the Supporting Information Dataset S4.

\section{Functional annotation}

Conserved protein domains were predicted using PFAM version 31 (Finn et al., 2016) and mapped to the corresponding gene ontology (GO) terms (Hunter et al., 2009). Proteases were predicted using the MEROPS database (Rawlings et al., 2016) with a blastp E-value cut-off of $10^{-5}$. Secretion signals and transmembrane domains were predicted using SignalP 4.1 (Petersen et al., 2011) and TMHMM 2.0c (Krogh et al., 2001), respectively.

The previously identified $A$. bisporus CAZYs and proteins involved in carbon metabolism (Patyshakuliyeva et al., 2013, 2015) were further annotated and supplemented as described in the Supporting Information Text S1. Over- and under-representation of functional annotation terms in sets of differentially regulated genes were identified using the Fisher Exact test. The Benjamini-Hochberg correction was used to correct for multiple testing using a $P$-value $<0.05$.

\section{Acknowledgements}

This research was supported by the Dutch Technology Foundation STW (Grants 11108 and 15493), which is part of the Netherlands Organization for Scientific Research (NWO), and which is partly funded by the Ministry of Economic Affairs.

\section{Author contributions}

Conceptualization: A.M.V., L.G.L., H.A.B.W. Methodology: A.M.V., R.J.B., K.C.H., H.S., L.G.L. Investigation: A.M.V., R.J.B., K.C.H., K.S. Formal Analysis: A.M.V., R.A.O. 
Writing: A.M.V., R.J.B., K.C.H., R.A.O., K.S., H.A.B.W. Visualization: A.M.V., R.J.B., K.C.H., K.S. Funding acquisition: H.A.B.W.

\section{References}

Alexander, N.J., McCormick, S.P., and Hohn, T.M. (1999) TRI12, a trichothecene efflux pump from Fusarium sporotrichioides: gene isolation and expression in yeast. Mol Gen Genet 261: 977-984.

Arantes, V., Jellison, J., and Goodell, B. (2012) Peculiarities of brown-rot fungi and biochemical Fenton reaction with regard to their potential as a model for bioprocessing biomass. Appl Microbiol Biotechnol 94: 323-338.

Atkey, P.T., and Wood, D.A. (1983) An electron microscope study of wheat straw composted as a substrate for the cultivation of the edible mushroom (Agaricus bisporus). J Appl Bacteriol 55: 293-304.

Bonnen, A.M., Anton, L.H., and Orth, A.B. (1994) Lignindegrading enzymes of the commercial button mushroom, Agaricus bisporus. Appl Environ Microbiol 60: 960-965.

Burton, K., Partis, M., Wood, D., and Thurston, C. (1997) Accumulation of serine proteinase in senescent sporophores of the cultivated mushroom, Agaricus bisporus. Mycol Res 101: 146-152.

Carrasco, J., García-Delgado, C., Lavega, R., Tello, M.L., De Toro, M., Barba-Vicente, V., et al. (2020) Holistic assessment of the microbiome dynamics in the substrates used for commercial champignon (Agaricus bisporus) cultivation. J Microbial Biotechnol 13: 1933-1947.

Castaño, J.D., Zhang, J., Anderson, C.E., and Schilling, J.S. (2018) Oxidative damage control as a brown rot fungus attacks wood using oxygen radicals. Appl Environ Microbiol 84: e01937-e01918.

Damaschke, K., and Becker, G. (1966) Rhythmen des sauerstoffverbrauchs von basidiomyceten. Mater Org 1: 275-290.

Van Erven, G., Hilgers, R., de Waard, P., Gladbeek, E.J., Van Berkel, W.J.H., and Kabel, M.A. (2019) Elucidation of in situ Ligninolysis mechanisms of the selective white-rot fungus Ceriporiopsis subvermispora. ACS Sustain Chem Eng 7: 16757-16764.

Finn, R.D., Coggill, P., Eberhardt, R.Y., Eddy, S.R., Mistry, J., Mitchell, A.L., et al. (2016) The Pfam protein families database: towards a more sustainable future. Nucleic Acids Res 44: D279-D285.

Floudas, D., Bentzer, J., Ahrén, D., Johansson, T., Persson, P., and Tunlid, A. (2020) Uncovering the hidden diversity of litter-decomposition mechanisms in mushroom-forming fungi. ISME J, 14, 1-14.

Goff, L., Trapnell, C., and Kelley, D. (2013) CummeRbund: analysis, exploration, manipulation, and visualization of cufflinks high-throughput sequencing data. $R$ package version 2 .

Grigoriev, I.V., Nikitin, R., Haridas, S., Kuo, A., Ohm, R., Otillar, R., et al. (2014) MycoCosm portal: gearing up for 1000 fungal genomes. Nucleic Acids Res 42: D699-D706.
Grimm, D., and Wösten, H.A.B. (2018) Mushroom cultivation in the circular economy. Appl Microbiol Biotechnol 102: 7795-7803.

Hammel, K.E., Kapich, A.N., Jensen, K.A., and Ryan, Z.C. (2015) Reactive oxygen species as agents of wood decay by fungi. Enzyme Microb Technol 30: 445-453.

Hammond, J.B.W., and Nichols, R. (1976) Carbohydrate metabolism in Agaricus bisporus (Lange) sing.: changes in soluble carbohydrates during growth of mycelium and sporophore. J Gen Microbiol 93: 309-320.

Hansen, L.D., MacFarlane, C., McKinnon, N., Smith, B.N., and Criddle, R.S. (2004) Use of calorespirometric ratios, heat per $\mathrm{CO} 2$ and heat per $\mathrm{O}_{2}$, to quantify metabolic paths and energetics of growing cells. Thermochim Acta 422: 55-61.

ten Have, R., and Teunissen, P.J. (2001) Oxidative mechanisms involved in lignin degradation by white-rot fungi. Chem Rev 101: 3397-3413.

ten Have, R., Wijngaard, H., Ariës-Kronenburg, N.a.E., Straatsma, G., and Schaap, P.J. (2003) Lignin degradation by Agaricus bisporus accounts for a $30 \%$ increase in bioavailable holocellulose during cultivation on compost. J Agric Food Chem 51: 2242-2245.

Heneghan, M.N., Burns, C., Costa, A.M.S.B., Burton, K.S., Challen, M.P., Bailey, A.M., and Foster, G.D. (2016) Functional analysis of Agaricus bisporus serine proteinase 1 reveals roles in utilization of humic rich substrates and adaptation to the leaf-litter ecological niche. Environ Microbiol 18: 4687-4696.

Herman, K.C., Wösten, H.A.B., Fricker, M.D., and Bleichrodt, R.J. (2020) Growth induced translocation effectively directs an amino acid analogue to developing zones in Agaricus bisporus. Fungal Biol. https://doi.org/10.1016/ j.funbio.2020.09.002.

Hofrichter, M. (2002) Review: lignin conversion by manganese peroxidase (MnP). Enzyme Microb Technol 30: 454-466.

Hunter, S., Apweiler, R., Attwood, T.K., Bairoch, A., Bateman, A., Binns, D., et al. (2009) InterPro: the integrative protein signature database. Nucleic Acids Res 37 : 211-215.

Jurak, E., Punt, A.M., Arts, W., Kabel, M.A., and Gruppen, H. (2015) Fate of carbohydrates and lignin during composting and mycelium growth of Agaricus Bisporus on wheat straw based compost. PLoS One 10: e0138909.

Kabel, M.A., Jurak, E., Mäkelä, M.R., and de Vries, R.P. (2017) Occurrence and function of enzymes for lignocellulose degradation in commercial Agaricus bisporus cultivation. Appl Microbiol Biotechnol 101: 4363-4369.

Kathiara, M., Wood, D.A., and Evans, C.S. (2000) Detection and partial characterization of oxalate decarboxylase from Agaricus bisporus. Mycol Res 104: 345-350.

Kersten, P.J., and Kirk, T.K. (1987) Involvement of a new enzyme, glyoxal oxidase, in extracellular $\mathrm{H} 2 \mathrm{O} 2$ production by Phanerochaete chrysosporium. J Bacteriol 169: 2195-2201.

Kim, D., Langmead, B., and Salzberg, S.L. (2015) HISAT: a fast spliced aligner with low memory requirements. Nat Methods 12: 357-360.

Korripally, P., Hunt, C.G., Houtman, C.J., Jones, D.C., Kitin, P.J., Cullen, D., and Hammel, K.E. (2015) 
Regulation of gene expression during the onset of ligninolytic oxidation by Phanerochaete chrysosporium on spruce wood. Appl Environ Microbiol 81: 7802-7812.

Krijgsheld, P., Nitsche, B.M., Post, H., Levin, A.M., Müller, W.H., Heck, A.J.R., et al. (2013) Deletion of flbA results in increased secretome complexity and reduced secretion heterogeneity in colonies of Aspergillus Niger. $J$ Proteome Res 12: 1808-1819.

Krogh, A., Larsson, B., Von Heijne, G., and Sonnhammer, E. L. (2001) Predicting transmembrane protein topology with a hidden Markov model: application to complete genomes. $J$ Mol Biol 305: 567-580.

Levin, J.Z., Yassour, M., Adiconis, X., Nusbaum, C., Thompson, D.A., Friedman, N., et al. (2010) Comprehensive comparative analysis of strand-specific RNA sequencing methods. Nat Methods 7: 709-715.

Morin, E., Kohler, A., Baker, A.R., Foulongne-Oriol, M., Lombard, V., Nagy, L.G., et al. (2012) Genome sequence of the button mushroom Agaricus bisporus reveals mechanisms governing adaptation to a humic-rich ecological niche. Proc Natl Acad Sci U S A 109: 17501-17506.

Moukha, S.M., Wösten, H.A.B., Asther, M., and Wessels, J. G. (1993) In situ localization of the secretion of lignin peroxidases in colonies of Phanerochaete chrysosporium using a sandwiched mode of culture. J Gen Microbiol 139: 969-978.

O'Connor, E., Owens, R.A., Doyle, S., Amini, A., Grogan, H., and Fitzpatrick, D.A. (2020) Proteomic investigation of interhyphal interactions between strains of Agaricus bisporus. Fungal Biol. 124, 579-591.

Osono, T. (2007) Ecology of ligninolytic fungi associated with leaf litter decomposition. Ecol Res 22: 955-974.

Parkhomchuk, D., Borodina, T., Amstislavskiy, V., Banaru, M., Hallen, L., Krobitsch, S., et al. (2009) Transcriptome analysis by strand-specific sequencing of complementary DNA. Nucleic Acids Res 37: e123.

Patyshakuliyeva, A., Jurak, E., Kohler, A., Baker, A., Battaglia, E., de Bruijn, W., et al. (2013) Carbohydrate utilization and metabolism is highly differentiated in Agaricus bisporus. BMC Genomics 14: 663.

Patyshakuliyeva, A., Mäkelä, M.R., Sietiö, O.M., de Vries, R. P., and Hildén, K.S. (2014) An improved and reproducible protocol for the extraction of high quality fungal RNA from plant biomass substrates. Fungal Genet Biol 72: 201-206.

Patyshakuliyeva, A., Post, H., Zhou, M., Jurak, E., Heck, A. J.R., Hildén, K.S., et al. (2015) Uncovering the abilities of Agaricus bisporus to degrade plant biomass throughout its life cycle. Environ Microbiol 17: 3098-3109.

Petersen, T.N., Brunak, S., von Heijne, G., and Nielsen, H. (2011) SignalP 4.0: discriminating signal peptides from transmembrane regions. Nat Methods 8: 785-786.

Presley, G.N., Panisko, E., Purvine, S.O., and Schilling, J.S. (2018) Coupling Secretomics with enzyme activities to compare the temporal processes of wood metabolism among white and brown rot fungi. Appl Environ Microbiol 84: e00159-e00118.

Presley, G.N., and Schilling, J.S. (2017) Distinct growth and secretome strategies for two taxonomically divergent brown rot fungi. Appl Environ Microbiol 83: e02987-e02916.
Rawlings, N.D., Barrett, A.J., and Finn, R. (2016) Twenty years of the MEROPS database of proteolytic enzymes, their substrates and inhibitors. Nucleic Acids Res 44: D343-D350.

Riley, R., Salamov, A.A., Brown, D.W., Nagy, L.G., Floudas, D., Held, B.W., et al. (2014) Extensive sampling of basidiomycete genomes demonstrates inadequacy of the white-rot/brown-rot paradigm for wood decay fungi. Proc Natl Acad Sci U S A 111: 9923-9928.

Roberts, A., Trapnell, C., Donaghey, J., Rinn, J.L., and Pachter, L. (2011) Improving RNA-Seq expression estimates by correcting for fragment bias. Genome Biol 12: R22.

Savoie, J.-M., Salmones, D., and Mata, G. (2007) Hydrogen peroxide concentration measured in cultivation substrates during growth and fruiting of the mushrooms Agaricus bisporus and Pleurotus spp. J Sci Food Agric 87: 1337-1344.

Schilling, J.S., Kaffenberger, J.T., Liew, F.J., and Song, Z. (2015) Signature wood modifications reveal decomposer community history. PLoS One 10: 120679.

Smith, R.S. (1973) Continuous automatic measurement of rhythms in fungal respiration using a gas chromatograph. Can J Bot 51: 701-710.

Sonnenberg, A.S.M., Sedaghat-Telgerd, N., Lavrijssen, B., Ohm, R.A., Hendrickx, P.M., Scholtmeijer, K., et al. (2020) Telomere-to-telomere assembled and centromere annotated genomes of the two main subspecies of the button mushroom Agaricus bisporus reveal especially polymorphic chromosome ends. Sci Rep 10: 1-15.

Stouthamer, A.H. (1973) A theoretical study on the amount of ATP required for synthesis of microbial cell material. Antonie Van Leeuwenhoek 39: 545-565.

Straatsma, G., Samson, R.a., Olijnsma, T.W., Op Den Camp, H.J., Gerrits, J.P., and Van Griensven, L.J. (1994) Ecology of Thermophilic fungi in mushroom compost, with emphasis on Scytalidium thermophilum and growth stimulation of Agaricus bisporus mycelium. Appl Environ Microbiol 60: 454-458.

Thornton, W.M. (1917) The relation of oxygen to the heat of combustion of organic compounds. London, Edinburgh, Dublin Philos Mag J Sci 33: 196-203.

Trapnell, C., Williams, B.A., Pertea, G., Mortazavi, A., Kwan, G., Van Baren, M.J., et al. (2010) Transcript assembly and quantification by RNA-Seq reveals unannotated transcripts and isoform switching during cell differentiation. Nat Biotechnol 28: 511-515.

Urzúa, U., Kersten, P.J., and Vicuña, R. (1998) Manganese peroxidase-dependent oxidation of Glyoxylic and oxalic acids synthesized by Ceriporiopsis subvermispora produces extracellular hydrogen peroxide. Appl Environ Microbiol 64: 68-73.

Vos, A.M., Heijboer, A., Boschker, H.T.S., Bonnet, B., Lugones, L.G., and Wösten, H.A.B. (2017a) Microbial biomass in compost during colonization of Agaricus bisporus. AMB Express 7: 12.

Vos, A.M., Jurak, E., Pelkmans, J.F., Herman, K., Pels, G., Baars, J.J., et al. (2017b) H2O2 as a candidate bottleneck for MnP activity during cultivation of Agaricus bisporus in compost. AMB Express 7: 124. 
Wood, D. (1983) Lignocellulose degradation during the life cycle of Agaricus bisporus. FEMS Microbiol Lett 20: 421-424.

Worrall, J.J., Anagnost, S.E., and Zabel, R.A. (1997) Comparison of wood decay among diverse lignicolous fungi. Mycologia 89: 199-219.

Wosten, H.A.B., Moukha, S.M., Sietsma, J.H., and Wessels, J.G.H. (1991) Localization of growth and secretion of proteins in Aspergillus Niger. $J$ Gen Microbiol 137: 2017-2023.

Zhang, J., Presley, G.N., Hammel, K.E., Ryu, J.-S., Menke, J.R., Figueroa, M., et al. (2016) Localizing gene regulation reveals a staggered wood decay mechanism for the brown rot fungus Postia placenta. Proc Natl Acad Sci U S A 113: 10968-10973.

Zhang, J., Silverstein, K.A.T., Castaño, J.D., Figueroa, M., and Schilling, J.S. (2019) Gene regulation shifts shed light on fungal adaption in plant biomass decomposers. MBio 10: e02176-e02119.

\section{Supporting Information}

Additional Supporting Information may be found in the online version of this article at the publisher's web-site:

Figure $\mathrm{S} 1 \mathrm{CO}_{2}$ production rate of $10 \mathrm{~g}$ PII-end compost that had (grey line) or had not (black line) been sterilized prior to inoculation with 4 spawn grains of $A$. bisporus. $\mathrm{CO}_{2}$ production was monitored after pre-growth at $25^{\circ} \mathrm{C}$ for 3 days.

Fig. S2. Respiratory bursts in $1 \mathrm{~kg}$ compost as measured by monitoring changes in temperature (black) and $\mathrm{CO}_{2}$ (grey).

Fig. S3. Temperature profile of compost (black line) and air in the incubation room (grey line) during vegetative growth (PIII and colonization of casing layer) and mushroom production (Venting, $1^{\text {st }}$ flush, and $2^{\text {nd }}$ flush) of $A$. bisporus. Respiratory bursts occurring in PIV are indicated with an arrow. These temperature peaks cannot be explained by peaks in the temperature of the incubation room.

Fig. S4. Examples of a compatible interactions of strain A15 (A), incompatible interaction of strains A15 and Bisp015 (B) and compatible interaction of strain Bisp015 (C).

Fig. S5. Temperature profiles of PIII compost used for RNA isolation in triplicate of inter-burst $(A-C)$, after-burst $(D-F)$, and burst (G-I) stages. Harvesting was done at time points indicated with an arrow. Temperature measurements were started 4 days after inoculation.
Table S1: Additionally released $\mathrm{CO}_{2}\left(\right.$ Add. $\left.\mathrm{CO}_{2}\right)$ and $\mathrm{O}_{2}$ (Add. $\mathrm{O}_{2}$ ) during bursts observed in the respirometer (Fig. 1). kJ released per burst was calculated assuming $455 \mathrm{~kJ} \mathrm{~mol}^{-1} \mathrm{O}_{2}$ (Hansen et al., 2004). Total $\mathrm{CO}_{2}$ production and $\mathrm{O}_{2}$ consumption was 831 and $1205 \mathrm{mmol} \mathrm{kg}^{-1}$ compost, respectively. The total $\mathrm{O}_{2}$ production during bursts was $255.15 \mathrm{mmol} \mathrm{kg}^{-1}$ compost and the total of additional $\mathrm{O}_{2}$ released during bursts was $95.65 \mathrm{mmol} \mathrm{kg}^{-1}$ compost

Table S2: Average (and standard deviation) of the duration of temperature increase, temperature increase, $\mathrm{kJ}$ released per burst assuming $60 \%$ water content, and $\mathrm{mmol} \mathrm{O}_{2} \mathrm{~kg}^{-1}$ compost released per burst. Values represent the average of the 6 sensors in Figure 2 for a burst around a time point. The maximum values for one of the peaks at $218 \mathrm{~h}$ are shown.

Table S3: Estimates of lignin, cellulose, and hemicellulose heat production upon mineralization. Numbers are based on data from (loelovich, 2018) and Thorntons Rule (Thornton, 1917).

Table S4: Estimated heat production as a consequence of lignin, cellulose, and hemicellulose loss during a typical PIII. Values for the PIII mass balance were taken from (Jurak et al., 2015). Conversion to heat production are based on Table S3.

Dataset S1: Enrichment analysis of GO and PFAM before, during, and after bursts.

Dataset S2: Expression of all CAZYs before, during, and after bursts.

Dataset S3: Total number and differentially expressed genes per CAZY class in 4 different FPKM ranges before, during, and after bursts.

Dataset S4: Expression of all genes before, during, and after bursts.

Dataset S5: Expression of protease genes before, during, and after bursts.

Dataset S6: Expression of beta-etherase (GST), hemethiolate peroxidase (HTP), and P450 genes before, during, and after bursts.

Dataset S7: Expression of transporter genes before, during, and after bursts.

Dataset S8: Expression of metabolic genes before, during, and after bursts.

Dataset S9: Expression of cell cycle related cyclin genes before, during, and after bursts

DATASETS A2: Supporting information 